\title{
Bridging anticoagulation for interruption of warfarin in a patient with atrial fibrillation
}

\author{
Eric Tseng MD, Mark A. Crowther MD MSc, Christopher M. Hillis MD
}

\begin{abstract}
A 78-year-old man with chronic nonvalvular atrial fibrillation presents to his family physician three weeks before a transurethral resection of the prostate for benign prostatic hypertrophy. His history includes hypertension and type 2 diabetes. He has no history of congestive heart failure, stroke or transient ischemic attack (TIA). His medications include warfarin, ramipril and metformin. He has a $\mathrm{CHADS}_{2}$ score of 3 and a $\mathrm{CHA}_{2} \mathrm{DS}_{2}$-VASc score of 4 (Box 1). ${ }^{1,2}$
\end{abstract}

\section{Should this patient's anticoagulation be interrupted for surgery?}

Both the procedural bleeding risk and anesthetic plan affect the decision of whether to interrupt anticoagulation. Prospective observational studies and randomized trials have shown that continuing anticoagulants for most skin, dental and cataract procedures is safe. ${ }^{3}$ Patients undergoing pacemaker or defibrillator insertion experience less bleeding when warfarin is continued perioperatively than when bridging with heparin is used. ${ }^{4}$ However, procedures with a major bleeding risk, including abdominal, thoracic, orthopedic and urologic surgeries, require anticoagulant interruption. ${ }^{3}$ As such, temporary warfarin cessation is appropriate for this patient.

\section{Should bridging anticoagulation be used?}

Guidelines suggest warfarin be stopped about five days before a major procedure. ${ }^{3}$ Anticoagulation is resumed when the postoperative bleeding risk is diminished, with full therapeutic effect delayed five to seven days. Bridging anticoagulation is the use of heparin (typically low-molecular-weight heparin $[\mathrm{LMWH}]$ ) to minimize time off anticoagulation and reduce the risk of thrombosis.

Guidelines suggest that patients at high risk of thromboembolism receive bridging anticoagulation. ${ }^{3}$ This group includes patients with a $\mathrm{CHADS}_{2}$ score of 5 or 6 , most patients with mechanical heart valves, and those with recent ischemic stroke or TIA, or recent deep vein thrombosis or pulmonary embolism (Box 2). ${ }^{3}$ However, a meta-analysis involving more than 12000 patients suggested that bridging is associated with an increased risk of overall and major bleeding, with no improvement in stroke risk. ${ }^{5}$ Data from a prospective observational registry of more than 7000 US outpatients with atrial fibrillation also showed that patients undergoing anticoagulation bridging had more bleeding events, with a higher risk of arterial thromboembolism, hospital admission and death. ${ }^{6}$

These observations were confirmed in the BRIDGE trial, where patients with atrial fibrillation undergoing elective invasive procedures or surgeries were randomly assigned to bridging with therapeutic LMWH or placebo during warfarin interruption. ${ }^{7}$ The incidence of major bleeding was three times higher in the bridged group (3.2\% v. $1.3 \%, p=0.005$ for superiority), and bridging was not associated with a reduction in the incidence of arterial thromboembolism $(0.3 \% \mathrm{v}$. $0.4 \%, p=0.01$ for noninferiority). ${ }^{7}$ These results suggest that bridging is associated with increased bleeding without reduction in perioperative stroke in most patients, and it would not be recommended for this patient.

In the BRIDGE trial, however, patient groups at high risk of stroke were either excluded or underrepresented (e.g., $97 \%$ of patients had a $\mathrm{CHADS}_{2}$ score of 4 or less). ${ }^{7}$ Until more data are available in these higher-risk groups, one could consider bridging anticoagulation in these patients, although deciding to forego bridging would also be reasonable.

In patients at moderate thrombotic risk, guidelines have suggested that decisions of whether to use bridging be made in consideration of individual patient factors and procedure-specific thrombotic risk. ${ }^{3}$ Results from the BRIDGE trial suggest that most patients at moderate risk, such as

\section{Box 1: Stratification for stroke risk in atrial fibrillation ${ }^{1,2}$}

The patient in this case has a $\mathrm{CHADS}_{2}$ score of 3 . This risk score quantifies stroke risk in nonvalvular atrial fibrillation. By this scheme, his estimated annual risk of stroke is 5.9\% (95\% confidence interval $4.6 \%-7.3 \%$ ).

The patient's $\mathrm{CHA}_{2} \mathrm{DS}_{2}$-VASc score is 4 . This risk score attempts to improve the estimation of stroke risk, particularly at lower $\mathrm{CHADS}_{2}$ scores, by considering additional risk factors such as sex and the presence of vascular disease. By this score, his estimated annual risk of stroke (adjusted for warfarin use) is $4.0 \%$. 
Box 2: Suggested risk stratification scheme for perioperative thromboembolism ${ }^{3}$

Risk category

(\% annual risk of thromboembolism)

Atrial fibrillation

Mechanical heart valve

Venous thromboembolism (VTE)

\begin{tabular}{|c|c|c|c|}
\hline $\begin{array}{l}\text { High } \\
(>10 \%)\end{array}$ & $\begin{array}{l}\text { CHADS }_{2} \text { score } 1 \text { of } 5 \text { or } 6 \text {; recent } \\
\text { (within } 3 \text { mo) stroke or transient } \\
\text { ischemic attack (TIA); rheumatic } \\
\text { valvular heart disease }\end{array}$ & $\begin{array}{l}\text { Any mitral valve prosthesis; any } \\
\text { caged-ball or tilting-disk aortic } \\
\text { valve prosthesis; recent (within } \\
6 \text { mo) stroke or TIA }\end{array}$ & $\begin{array}{l}\text { Recent (within } 3 \mathrm{mo} \text { ) VTE; severe } \\
\text { thrombophilia (e.g., deficiency of protein C, } \\
\text { protein S or antithrombin; antiphospholipid } \\
\text { antibodies; multiple abnormalities) }\end{array}$ \\
\hline $\begin{array}{l}\text { Moderate } \\
(5 \%-10 \%)\end{array}$ & $\mathrm{CHADS}_{2}$ score $^{1}$ of 3 or 4 & $\begin{array}{l}\text { Bi-leaflet aortic valve prosthesis and } \\
\geq 1 \text { risk factor (atrial fibrillation, } \\
\text { prior stroke or TIA, hypertension, } \\
\text { diabetes, congestive heart failure, } \\
\text { age }>75 \mathrm{yr} \text { ) }\end{array}$ & $\begin{array}{l}\text { VTE within past 3-12 mo; nonsevere } \\
\text { thrombophilia (heterozygous factor V Leiden } \\
\text { or prothrombin gene mutation); recurrent } \\
\text { VTE; active cancer (treated within } 6 \text { mo or } \\
\text { palliative) }\end{array}$ \\
\hline $\begin{array}{l}\text { Low } \\
(<5 \%)\end{array}$ & $\begin{array}{l}\mathrm{CHADS}_{2} \text { score } \\
\text { (no prior stroke or } 0 \text { to } 2 \\
\text { TIA) }\end{array}$ & $\begin{array}{l}\text { Bi-leaflet aortic valve prosthesis } \\
\text { without atrial fibrillation and no } \\
\text { other risk factors for stroke }\end{array}$ & VTE $>12$ mo previous \\
\hline
\end{tabular}

Reproduced from Douketis et al. ${ }^{3}$ with permission from the American College of Chest Physicians.

Box 3: Choosing Wisely Canada* recommendation from the Canadian Hematology Society ${ }^{8}$

During interruption of warfarin anticoagulation for procedures, do not "bridge" with full-dose low-molecular weight heparin or unfractionated heparin unless the risk of thrombosis is high.

- Bridging anticoagulation has been shown to increase bleeding without reducing rates of perioperative arterial thromboembolism. Therefore, bridging should not be offered unless the thrombotic risk exceeds the bleeding risk.

*www.choosingwiselycanada.org/recommendations/hematology/

this patient, do not benefit from bridging. The Canadian Hematology Society suggests that bridging not be offered unless the thrombotic risk exceeds the bleeding risk (Box 3). ${ }^{8}$

\section{What if this patient had been taking a direct oral anticoagulant?}

The periprocedural management of patients taking direct oral anticoagulants has been reviewed elsewhere. ${ }^{9}$ Although bridging studies did not include patients taking direct oral anticoagulants, similar principles around decisions to withhold anticoagulation may be used. Given the rapid onset and shorter half-life of direct oral anticoagulants, bridging with heparin (or LMWH) is unnecessary and may lead to postoperative bleeding if reinstituted prematurely following a procedure. ${ }^{10}$

\section{Case revisited}

The patient's warfarin was held five days before his procedure without bridging anticoagulation. The surgery was uncomplicated with minimal blood loss, and his warfarin was restarted the next day with no bridging anticoagulation.

\section{References}

1. Gage BF, Waterman AD, Shannon W, et al. Validation of clinical classification schemes for predicting stroke: results from the National Registry of Atrial Fibrillation. JAMA 2001;285:2864-70.
2. Lip GY, Nieuwlaat R, Pisters R, et al. Refining clinical risk stratification for predicting stroke and thromboembolism in atrial fibrillation using a novel risk factor-based approach: the Euro Heart Survey on Atrial Fibrillation. Chest 2010;137:263-72.

3. Douketis JD, Spyropoulos AC, Spencer FA, et al. Perioperative management of antithrombotic therapy: antithrombotic therapy and prevention of thrombosis, 9th ed: American College of Chest Physicians evidence-based clinical practice guidelines. Chest 2012;141: e326S-e350S.

4. Birnie DH, Healey JS, Wells GA, et al. Pacemaker or defibrillator surgery without interruption of anticoagulation. $N$ Engl J Med 2013;368:2084-93.

5. Siegal D, Yudin J, Kaatz S, et al. Periprocedural heparin bridg ing in patients receiving vitamin $\mathrm{K}$ antagonists: systematic review and meta-analysis of bleeding and thromboembolic rates. Circulation 2012;126:1630-9.

6. Steinberg BA, Peterson ED, Kim S, et al. Use and outcomes associated with bridging during anticoagulation interruptions in patients with atrial fibrillation: findings from the Outcomes Registry for Better Informed Treatment of Atrial Fibrillation (ORBITAF). Circulation 2015;131:488-94.

7. Douketis JD, Spyropoulos AC, Kaatz S, et al. Perioperative bridging anticoagulation in patients with atrial fibrillation. $N$ Engl J Med 2015;373:823-33.

8. Hillis CM, Schimmer AD, Couban S, et al. The Canadian Choosing Wisely campaign: the Canadian Hematology Society's top five tests and treatments. Ann Hematol 2015;94:541-5.

9. Spyropoulos AC, Douketis JD. How I treat anticoagulated patients undergoing an elective procedure or surgery. Blood 2012; 120:2954-62.

10. Douketis JD, Healey JS, Brueckmann M, et al. Perioperative bridging anticoagulation during dabigatran or warfarin interruption among patients who had an elective surgery or procedure. Substudy of the RE-LY trial. Thromb Haemost 2015;113:625-32.

Affiliations: Department of Hematology (Tseng), University of Toronto, Toronto, Ont.; Departments of Pathology and Molecular Medicine (Crowther) and of Oncology (Hillis), McMaster University, Hamilton, Ont.

Contributors: All of the authors contributed substantially to the article conception and design, drafted the article or revised it critically for important intellectual content, gave final approval of the version to be published and agreed to act as guarantors of the work.

CMAJ is collaborating with Choosing Wisely Canada (www.choosingwiselycanada.org), with support from Health Canada, to publish a series of articles describing how to apply the Choosing Wisely Canada recommendations in clinical practice. 